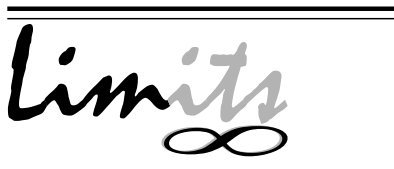

J. Math. and Its Appl.

ISSN : 1829-605X

Vol. 3, No. 1, May 2006, 41-48

\title{
Analisa Perluasan Model Rosenzweig-MacArthur dengan menggunakan Perturbasi Singular
}

\author{
Endah Asmawati \\ Departemen MIPA \\ Universitas Surabaya (Ubaya) \\ e_61113@yahoo.com
}

\begin{abstract}
Dalam membahas rantai makanan dua dimensi (prey - predator), biasanya digunakan model rantai makanan Rosenzweig-MacArthur. Untuk mendekati keadaan sebenarnya, akan ditambahkan satu variabel baru (predator tingkat dua) pada model itu. Model ini disebut perluasan model Rosenzweig-MacArthur. Dinamika dari perluasan model RosenzweigMacArthur dapat diketahui dengan terlebih dahulu membentuk model menjadi nondimensional, kemudian digunakan metode perturbasi singular. Dengan metode ini dapat diketahui kondisi yang stabil dari sistem, dimana tidak terjadi kepunahan dari ketiga spesies tersebut (prey-predator tingkat satu-predator tingkar dua).
\end{abstract}

Kata Kunci:model Rosenzweig-MacArthur, perturbasi singular

\section{Pendahuluan}

Pada rantai makanan, mengetahui model dan dinamika dari model matematika merupakan hal yang penting. Melalui model dapat dipelajari keterkaitan atau hubungan antara variabel yang satu dengan variabel yang lain. Dinamika dari 
model diperoleh dengan menganalisa model menggunakan pendekatan sistem dinamik. Secara umum, model dasar interaksi dua spesies populasi yang sering dibahas adalah model rantai makanan Rosenzweig-MacArthur, yaitu :

$$
\begin{aligned}
\dot{X} & =r X\left(1-\frac{X}{K}\right)-\frac{p X}{H+X} Y \\
\dot{Y} & =\frac{b p X}{H+X} Y-d Y-s Y Y
\end{aligned}
$$

dimana $X$ adalah jumlah prey dan $Y$ adalah jumlah predator. $r$ laju pertumbuhan perkapita maksimum dan $K$ carrying capacity. $p$ adalah laju pemangsaan saturation ketika $X$ abundant dan $H$ adalah konstan yang menyatakan setengah dari laju saturation. $s Y Y$ adalah besar kecilnya interaksi antar predator dan $b$ disebut rasio birth-to-consumption. Pada model Rosenzweig-MacArthur, analisa skala waktu (metode perturbasi singular) dilakukan berdasarkan asumsi the trophic time diversification yang menyatakan bahwa pertumbuhan prey lebih cepat daripada predator $[2,3,4,5,7,8]$ sehingga siklus kehidupan atau keberadaan semua spesies dapat dipertahankan. Dalam tulisan ini model yang akan dibahas adalah perluasan dari model Rosenzweig-MacArthur, yaitu penambahan variabel baru (predator tingkat dua) pada model Rosenzweig-MacArthur sehingga menjadi sistem tiga dimensi. Dengan menggunakan perluasan model Rosenzweig-MacArthur dapat dianalisa kondisi sistem sehingga bisa diperoleh kondisi yang stabil. Yang dimaksud kondisi stabil disini adalah tidak terjadi kepunahan antara prey, predator tingkat satu dan predator tingkat dua.

\section{Model Rantai Makanan}

Dengan ditambahkannya satu variabel predator tingkat dua pada model rantai makanan Rosenzweig-MacArthur (dua dimensi), maka model akan berubah menjadi :

$$
\begin{aligned}
\dot{X} & =r X\left(1-\frac{X}{K}\right)-\frac{p_{1} X}{H_{1}+X} Y \\
\dot{Y} & =Y\left(\frac{b_{1} p_{1} X}{H_{1}+X}-d_{1}-s_{1} Y\right)-\frac{p_{2} Y}{H_{2}+Y} Z \\
\dot{Z} & =Z\left(\frac{b_{2} p_{2} Y}{H_{2}+Y}-d_{2}-s_{2} Z\right)
\end{aligned}
$$

dengan $X, Y, Z$ masing-masing adalah densitas dari prey, predator tingkat satu dan predator tingkat dua. $r$ adalah rata-rata pertumbuhan perkapita dari spesies prey, $\mathrm{K}$ carrying capacity dari lingkungan terhadap prey. $H_{i}$ konstan, $d_{i}$ ratarata kematian perkapita dari spesies predator tingkat satu dan predator tingkat 
dua. Untuk menganalisa model pada Persamaan 1, dilakukan transformasi menjadi bentuk nondimensional dengan :

$$
\begin{gathered}
t \rightarrow b_{1} p_{1} t, \quad x=\frac{X}{K}, \quad y=\frac{Y}{Y_{0}}, \quad z=\frac{Z}{Z_{0}}, \quad \text { dengan } \quad Y_{0}=\frac{r K}{p_{1}}, \quad Z_{0}=\frac{b_{1} r K}{p_{2}} \\
\beta_{1}=\frac{H_{1}}{K}, \quad \beta_{2}=\frac{H_{2}}{Y_{0}}, \quad \delta_{1}=\frac{d_{1}}{b_{1} p_{1}}, \quad \delta_{2}=\frac{d_{2}}{b_{2} p_{2}} \\
\sigma_{1}=\frac{s_{1} Y_{0}}{b_{1} p_{1}}, \quad \sigma_{2}=\frac{s_{2} Z_{0}}{b_{2} p_{2}}, \quad \zeta=\frac{b_{1} p_{1}}{r}, \quad \varepsilon=\frac{b_{2} p_{2}}{b_{1} p_{1}}
\end{gathered}
$$

dengan $Y_{0}$ adalah predation capacity dari predator tingkat satu, $Z_{0}$ adalah predation capacity dari predator tingkat dua. Parameter $\beta_{1}$ adalah konstanta nondimensi yang mengukur carrying capacity dari prey. $\beta_{2}$ adalah konstanta nondimensi yang mengukur predation capacity dari predator tingkat satu. Diasumsikan $0<\beta_{1}<1$ dan $0<\beta_{2}<1,0<\delta_{1}<1$ dan $0<\delta_{2}<1$. Karena laju reproduksi maksimum dari prey lebih cepat daripada predator tingkat satu maka dapat diabaikan efek interferensi intraspesifik dari predator tingkat satu dan diasumsikan $s_{1}=0$, sehingga sistem menjadi :

$$
\begin{aligned}
\zeta \dot{x} & =x\left(1-x-\frac{y}{\beta_{1}+x}\right) \\
\dot{y} & =y\left(\frac{x}{\beta_{1}+x}-\delta_{1}-\frac{z}{\beta_{2}+y}\right) \\
\dot{z} & =\varepsilon z\left(\frac{y}{\beta_{2}+y}-\delta_{2}-\sigma_{2} z\right)
\end{aligned}
$$

Bentuk nondimensional ini mengurangi jumlah parameter dari 12 menjadi 8 . Variabel $x, y, z$ disebut komponen fast, intermediate dan slow dari sistem 2 . Dalam pembahasan, yang akan dibicarakan adalah kondisi pada oktan satu yaitu $x \geq 0, y \geq 0, z \geq 0$.

\section{Perturbasi Singular}

Sistem nondimensional 2 dengan parameter $0<\varepsilon \ll 1$ dan $0<\zeta \ll 1$ dapat diselesaikan dengan metode perturbasi singular. Pada metode ini sistem mempunyai skala waktu yang berbeda. Perbedaan skala waktu dilakukan dengan mengkonstruksi sistem tiga dimensi menjadi dua dimensi kemudian satu dimensi yang diperoleh saat $\zeta \rightarrow 0$ atau $\varepsilon \rightarrow 0$ atau kedua-duanya mendekati nol $(\zeta \rightarrow 0$ dan $\varepsilon \rightarrow 0$ ). 


\section{Dinamika prey-predator tingkat satu}

Untuk mendapatkan fast subsistem dari persamaan 2, dilakukan rescaling $\bar{t}=\frac{t}{\zeta}$ dan mengambil $\zeta \rightarrow 0$ pada persamaan yang baru, sehingga diperoleh :

$$
\dot{x}=x f(x, y), \quad \dot{y}=0, \quad \dot{z}=0
$$

Sistem ini menjadi sistem berdimensi satu dalam variabel $x$, sedangkan $y$ dan $z$ sebagai parameter. Orbit dari fast subsistem dicari dari nullcline $x$, yaitu saat $\dot{x}=0$ atau $x f(x, y)=0$ yang menghasilkan $x=0$ atau $f(x, y)=0$. Kurva $f(x, y)=0$ berupa silinder parabola

$$
y=(1-x)\left(\beta_{1}+x\right)
$$

yang mempunyai titik dan nilai maksimum

$$
\bar{x}=\frac{1-\beta_{1}}{2}, \quad \bar{y}=\frac{\left(1+\beta_{1}\right)^{2}}{4}
$$

Nullcline nontrivial dan trivial akan berpotongan pada titik $\left(0, \beta_{1}\right)$. Orbit dari fast subsistem bergerak dalam arah $x$. Untuk daerah diatas kurva $f=0$ (daerah I pada Gambar 1), akan diperoleh nilai $f<0$. Karena $x>0$ maka $\dot{x}<0$ (arah panah kekiri). Sedangkan untuk daerah dibawah kurva $f=0$ (daerah II pada Gambar 1), diperoleh nilai $f>0$. Hal ini mengakibatkan $\dot{x}>0$ (arahnya kekanan). Untuk lebih jelasnya, dengan nilai awal yang berbeda-beda, arah orbit fast subsistem (panah tiga) dapat dilihat pada Gambar 1

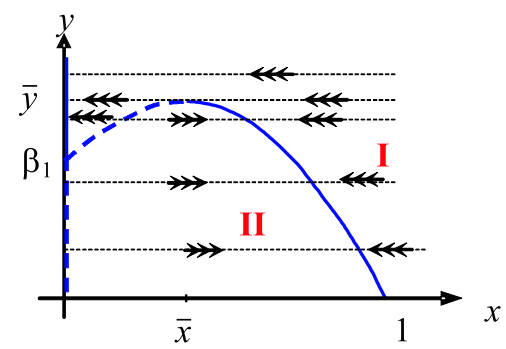

Gambar 1: Orbit fast subsistem

Dari gambar diatas terlihat bahwa nullcline $x=0$, untuk $y>\beta_{1}$ merupakan bagian yang stabil. Hal ini terlihat dengan arah panah yang selalu menuju ke bagian tersebut. Sedangkan $0<y<\beta_{1}$ merupakan bagian yang tidak stabil. Untuk nullcline $f=0$, stabilitas terbagi menjadi dua bagian, yang pertama $0<x<\bar{x}$ adalah merupakan bagian yang tidak stabil. Sedang $\bar{x}<x \leq 1$ merupakan bagian yang stabil. Dengan demikian titik $(\bar{x}, \bar{y})$ disebut sebagai titik saddle singular dan $\left(0, \beta_{1}\right)$ disebut titik transkritikal. Untuk selanjutnya $y=\beta_{1}$ dinotasikan dengan $y_{\text {trn }}$. 
Untuk mendapatkan dinamika dari predator tingkat satu, ambil $\zeta \rightarrow$ dan $\varepsilon \rightarrow$ 0 pada persamaan 2. Akan diperoleh intermediate subsistem dalam y sebagai berikut:

$$
0=x f(x, y), \quad \dot{y}=y g(x, y, z), \quad \dot{z}=0
$$

Terlihat bahwa orbit intermediate subsistem terletak pada manifold nullcline- $x$, $x=0$ dan $f=0$. Artinya orbitnya terletak pada permukaan nullcline- $x$ dengan nilai $z$ konstan.

Ada beberapa kasus yang dapat diamati pada orbitnya dengan nilai $z$ yang berbeda-beda (Gambar 2). Grafik fungsi $g=0$ akan berubah dengan berubahnya nilai $z$, sedangkan parabola $f=0$ tidak akan berubah (karena tidak bergantung pada nilai $z$ ). Diatas kurva $g=0$ akan diperoleh $g>0$. Karena $y>0$ maka $\dot{y}>0$ (arah panah naik). Sedangkan dibawah kurva $g=0$ didapatkan $g<0$ sehingga $\dot{y}<0$ (arah panah turun). Bentuk dari orbit slow subsistem (panah dua) dapat dilihat pada Gambar 2.
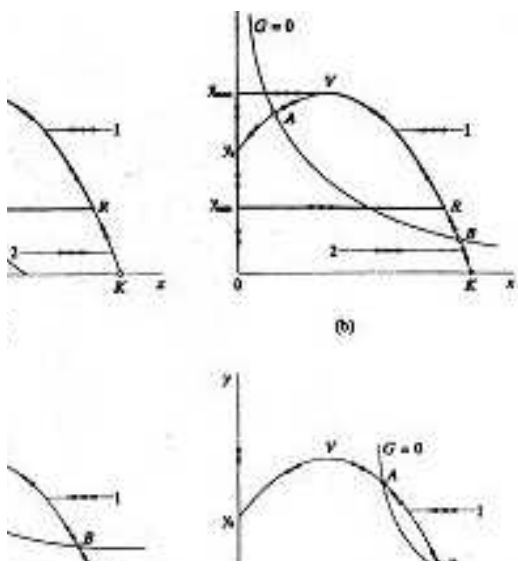

Gambar 2: Orbit dari fast-intermediate sub sistem (nilai z naik dari a sampai d)

Pada Gambar 2-c terlihat bahwa intermediate orbit pada nullcline $x=0$, setelah melewati $y_{t r n}$ tidak langsung lompat ke bagian yang stabil dari parabola mengikuti fast orbit. Namun hal ini terjadi pada titik $y=y_{s p k}$ yang terletak dibawah $y_{t r n}$. Kejadian ini dikenal dengan Pontryagin's delay of lost stability (PDLS). Untuk menghitung $y_{s p k}$ perlu diketahui nilai $y$ yang menjadi titik pertama kali pada sumbu $y$ dimana fast orbit sampai, dalam hal ini titik tersebut adalah 
$\bar{y} \cdot y_{s p k}$ merupakan nilai yang memenuhi :

$$
\int_{y s p k}^{\bar{y}} \frac{f(0, y)}{y g(0, y, z)} d y=0
$$

\section{Dinamika predator tingkat dua}

Dinamika predator tingkat dua diperoleh dengan rescaling $\bar{t} \rightarrow \varepsilon t$ pada Persamaan 2 dan mengambil $\varepsilon \rightarrow 0$ pada persamaan baru. Akan diperoleh :

$$
0=x f(x, y), \quad 0=y g(x, y, z), \dot{z}=z h(y, z)
$$

Dari persamaan diatas terlihat bahwa orbit dari slow subsistem terletak pada perpotongan nullcline- $x$ dan nulline- $y$. Perpotongan dari ketiga bidang nullcline nontrivial akan menghasilkan sebuah titik $P_{f}$ seperti terlihat pada Gambar 3. Diatas bidang $h=0$ akan diperoleh $\dot{z}>0$ dan dibawah bidang $h=0$ akan diperoleh $\dot{z}<0$. Titik $(1,0, \underline{z})$ atau pada Gambar 3 disebut titik transkritikal. Orbit setelah melewati titik ini akan mengalami PDLS, seperti yang terjadi sebelumnya. Titik dimana orbit akan mengikuti intermediate orbit dinotasikan dengan $z_{B}$ dan titik dari intermediate orbit menjadi slow orbit dinotasikan dengan $z_{A}$. Jika $z_{A}$ diketahui maka $z_{B}$ dapat dihitung dengan persamaan :

$$
\int_{z_{A}}^{z_{B}} \frac{g(1,0, z)}{z h(0, z)} d z=0
$$

Sehingga orbit singular dari slow-intermediate subsistem yang terjadi bila dilihat dari depan bidang $Y O Z$ adalah seperti yang terlihat pada Gambar 3

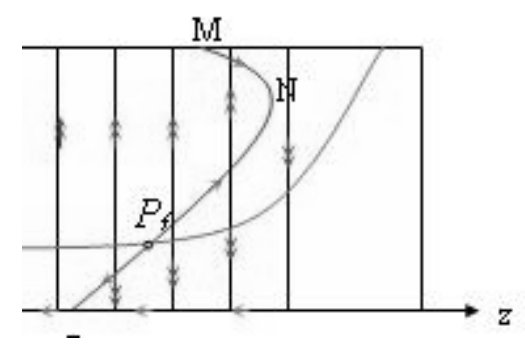

Gambar 3: Orbit singular slow-intermediate subsistem dalam dua dimensi

Apabila ketiga orbit (slow-intermediate-fast) digambarkan secara bersamasama, maka orbit singular yang terjadi terlihat seperti pada Gambar 4 


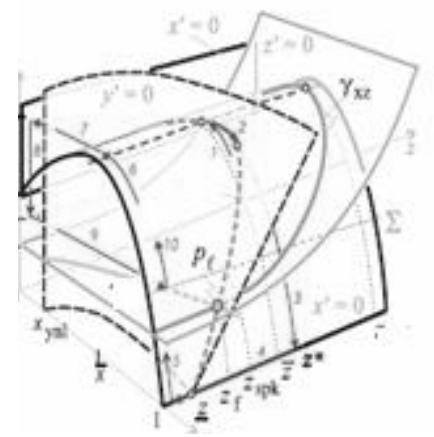

Gambar 4: Orbit singular dari sistem 2

Dari gambar tersebut terlihat bahwa orbit singular yang terjadi mengikuti garis merah yang ada. Orbit dengan notasi 1,3,5,6,8,10 adalah intermediate orbit, 7 dan 9 adalah fast orbit, dan 2 dan 4 adalah slow orbit.

\section{References}

[1] Deng Bo, Equilibriumizing all food chain chaos and the top-predator stabilization principle, 28 March 2005.

[2] Deng Bo, Food chain chaos due to junction-fold point, Chaos 11, 514-525 (2001).

[3] Deng Bo and Hines G., Food chain chaos due to Shilnikov orbit, Chaos 12, 533-538 (2002).

[4] Deng Bo and Hines G., Food chain chaos due to transcritical point, Chaos 13, 578-585 (2003).

[5] Deng Bo, Food chain chaos with canard explosion, Chaos, 14, 1083-1092 (2004).

[6] De Feo, O. and Rinaldi S., Singular homoclinic bifurcations in tritrophic food chains, Mathematical Biosciences 148 (1998) 7-20.

[7] Muratori S. and Rinaldi S. , Low - and high - frequency oscillations in threedimensional foo d chain system, SIAM J. Appl. Math. 52, 1688-1706 (1992). 
[8] Rinaldi S. and Muratori S., Slow-fast limit cycles in predator-prey models, Ecol. Model. 61, 287-308 (1992). 